\title{
A LCIA Model Considering Pollution Transfer Phenomena
}

\author{
$\mathrm{Xi} \mathrm{Yu}{ }^{1}$, Aicha Sekhari ${ }^{1}$, Antoine Nongaillard ${ }^{1}$, Abdelaziz Bouras ${ }^{1}$, Suiran $\mathrm{Yu}^{2}$, \\ and Qingyan Yang ${ }^{2}$ \\ ${ }^{1}$ University Lyon 2 Lumière, DISP laboratory, France \\ \{xi.yu, aicha.sekhari, antoine.nongaillard, \\ abdelaziz.bouras\} @univ-lyon2.fr \\ ${ }^{2}$ School of Mechanical and Power Engineering, Shanghai Jiao Tong University, China \\ \{yqy0805, sryu\} esjtu.edu.cn
}

\begin{abstract}
Due to market pressure and government regulations, environmental consciousness in manufacturing is becoming increasingly important. Currently, the global environmental impact (EI) of a product is a crucial criterion to judge its environmental performance. Many models were proposed in the last three decades to evaluate the global EI of products, but none of them considers the pollution transfer phenomena (PTP) of product's material flow. PTP refers to the EIs propagate from one phase to another one caused by different processes on the product's materials in different phases. PTP may have a consequence of EIs reduce in one phase but increase in other phases. The outcome will severely influence on the global EI of a product. Based on a PCB (printed circuit board) product case study, this paper proposes a new simplified life cycle impact assessment (LCIA) model which can help enterprises evaluate the global EI of product by considering the PTP in the whole product life cycle (PLC).
\end{abstract}

Keywords: PLC, PCB, PTP, LCA, LCIA, PLM, MFA.

\section{$1 \quad$ Introduction}

Following the increased environmental awareness of society, legislations are published to restrict the pollution emission through the whole lifecycle of products[1], such as waste of electrical and electronic equipment (WEEE), reduction of hazardous substances in EEEs (RoHS) and energy using products (EuP). Many models have been proposed to assess the EIs of products in the last three decades. Among these models, LCA is more accepted in Industry because this method is a quantitative analysis method based on factual information and on models of practical processes. The importance of different lifecycle phases and environmental emissions we are concerned about can be evaluated by the judgment process of LCA [2]. The implementation of LCA in different industries has boomed since last three decades. In these studies, the EIs of a product are assessed separately at each phase of the PLC since actors at a given phase cannot get easily the product data related to other PLC phases $[3 ; 4 ; 5 ; 6]$.

Material flow analysis (MFA) reveals that the materials using in one product has its own material metabolism based on two fundamental and well-established scientific 
principles: system approach and mass balance. Any changes in one phase of PLC will has some consequences in other phases [7]. Cheah and colleagues examined the impact of expanded use of aluminium in the car fleet on energy resources. Using aluminium instead of steel reduced energy consumption and EIs in the use phase hence it increased fuel efficiency by reducing the weight of the car. But this is countered by the larger energy use and more EIs in the production phase [8]. Thus, the PTPs accompany with material flow in the product should take into account when assess the global environmental emissions of products.

After this introduction, section 2 discusses several environmental assessment models. Section 3 proposes an assessment model considering the PTP through the whole PLC. Section 4 presents a case study based on a PCB product, followed by conclusions.

\section{Literature Review}

Over the past decades, several environmental analysis methods have been developed and utilized as following:

LCA [9] may be the most famous quantitative method for evaluating environmental requirements. This method takes into account the whole product life cycle and can help enterprises to get accurate environmental information about the product. First, LCA chooses the environmental indicators that correspond to the enterprise objectives; then it analyzes the product based on the special data inventory; finally LCA provides an environmental interpretation of the product. However, a complete, quantitative full LCA has never been accomplished since its tedious, expensive and time-consuming attributes. All LCAs conducted now are simplified some way by ignoring some phases of PLC [10]. Hence they cannot get a global environmental performance of products.

MET Matrix [11] is a qualitative model which is used to summarize the EI at each stage of the product's lifecycle. MET Matrix classifies the environmental problems into three categories: Material cycle, Energy use and Toxic emission. By analyzing the importance degree of the environmental problems at each stage of the PLC, this method can generate structured qualitative information on the environmental aspects associated with the production, use and disposal of a product. However, this method is largely based on the available knowledge, the experience of the team performing the analysis and cannot provide a quantitative result.

The ERPA matrix [12] is a tool used to estimate a product's potential improvements in environmental performance. As shown in Table 1, rows in the matrix represent the stages of the life cycle, and columns stand for environmental concerns. By evaluating each cell in the matrix, the product's total environmental responsibility ( $\left.R_{e r p}\right)$ is computed as the sum of the matrix element values $\left(M_{i j}\right)$ :

$$
R_{e r p}=\sum_{i} \sum_{j} M_{i j}
$$

Where $i$ represents the life cycle stage and $j$ represents the environmental concerns fields, respectively. 
Table 1. The environmentally responsible product assessment matrix

\begin{tabular}{llllll}
\hline Life cycle stage & $\begin{array}{l}\text { Materials } \\
\text { choice }\end{array}$ & $\begin{array}{l}\text { Energy } \\
\text { use }\end{array}$ & $\begin{array}{l}\text { Solid } \\
\text { residues }\end{array}$ & $\begin{array}{l}\text { Liquid } \\
\text { residues }\end{array}$ & $\begin{array}{l}\text { Gaseous } \\
\text { residues }\end{array}$ \\
\hline Premanufacture & 1.1 & 1.2 & 1.3 & 1.4 & 1.5 \\
Product manufacture & 2.1 & 2.2 & 2.3 & 2.4 & 2.5 \\
Product delivery & 3.1 & 3.2 & 3.3 & 3.4 & 3.5 \\
$\begin{array}{l}\text { Product use } \\
\text { Refurbishment, recycling, } \\
\text { disposal }\end{array}$ & 4.1 & 4.2 & 4.3 & 4.4 & 4.5 \\
\hline
\end{tabular}

In the ERPA matrix, each element is assigned a rating from 0 (highest impact) to 4 (lowest impact) according to a checklist. Hence, this method is qualitative and cannot provide accurate results of the global environmental performance of products.

The Ten Golden Rules[13] is a summary of numerous guidelines that can be found in company guidelines and in handbooks of different origins. These rules must be customized to be directly useful in product development. Meanwhile, these rules are only some common criteria to help users reduce the EI of product during the design phase. This method does not evaluate the environmental performance of products.

All of the aforementioned models either only consider one phase of PLC, or only conduct a qualitative study. The problems of evaluate global EI are: 1. the product data belongs to different actors in different phases and most of these data are business secret. It is difficult for enterprises to collect a set of complete site data; 2 . the product data in different phases are very massive and hard to find out the PTP factor. So it's hard for enterprises calculate the influence effect among different phases.

\section{LCIA Model Considering PTP}

In order to get more accurate global EI, we proposed a simplified LCIA (Life Cycle Impact Assessment) model which considers the Pollution Transfer Phenomena (PTP) factors through the whole PLC. This model uses the concept of the MFA (Material Flow Analysis) method to analyze the most important environmental factors of products. Based on the data gathered from PLM (Product Lifecycle Management) system and general design parameters, the mass of materials in each phase of PLC can be calculated. Then, LCA method helps to evaluate the global EI of products.

MFA is an effective tool to assess the physical consequences of human activities in the field of industrial ecology, where it is used on different spatial and temporal scales[7]. So far, efforts by the MFA community have been mainly academic, but this theory proved the materials using in one product has its own material metabolism. This outcome gives a strong support to analyze the global environmental impacts of products.

PLM integrates people, data, processes and business systems, and provides a product information backbone for companies and their extended enterprise [14]. In PLM systems, the product data such as mass of materials, product parameters, assembling parameters, process parameters, etc. can be collected. On the basis of the information of product, the mass of discharge materials in each phase can be calculated. Thus, we can choose proper characterization factors to convert the mass of the discharge materials into EI results. 
From the concept of MFA, the materials in products have its own material metabolism; any change in this context will have uncertain influence in terms of PLC. As shown in Figure $1 \mathrm{~B}$, the actors reduced the EIs in the manufacturing phase compared with the reference design in Figure $1 \mathrm{~A}$. But due to the material in one phase changed, the EIs brought by this material in other phases will be changed correspondingly. Consequently, the EIs increased in raw materials and end-of-life phases and make the global EIs of products changed unpredictably. Hence, the PTP related with material flow must be taken into account to calculate the global EIs of the product.

To get a more accurate global score of products environmental impacts, a model considering PTP which combined with the concept of LCA, PLM, and MFA is proposed as shown in Figure 2. As shown in Figure 2, by using the MFA theory to analyze the PTP of materials in the PLC, the mass of discharge materials in each PLC phase can be calculated based on the product data get from PLM. By choosing proper characterization factor, the mass of discharge materials in each phase can be converted into EIs. Then use the LCA method to calculate the EI of each phase. Finally, aggregate the EI of each phase into the global EI.
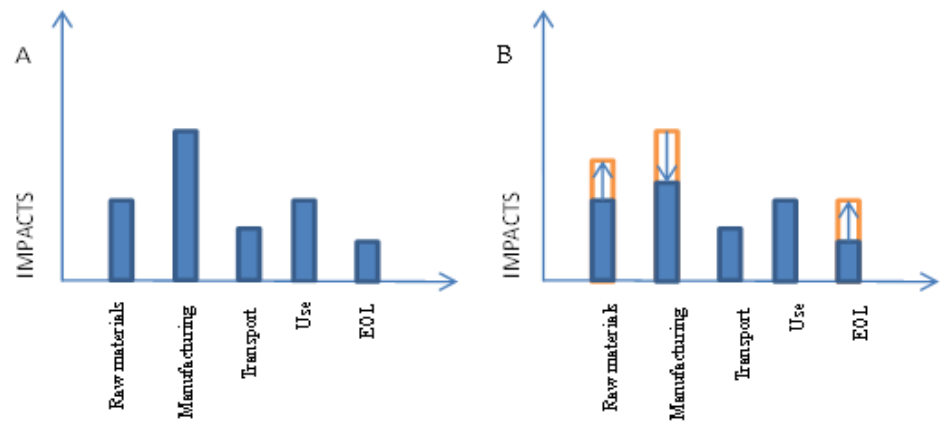

Fig. 1. Pollution transfer impacts in PLC

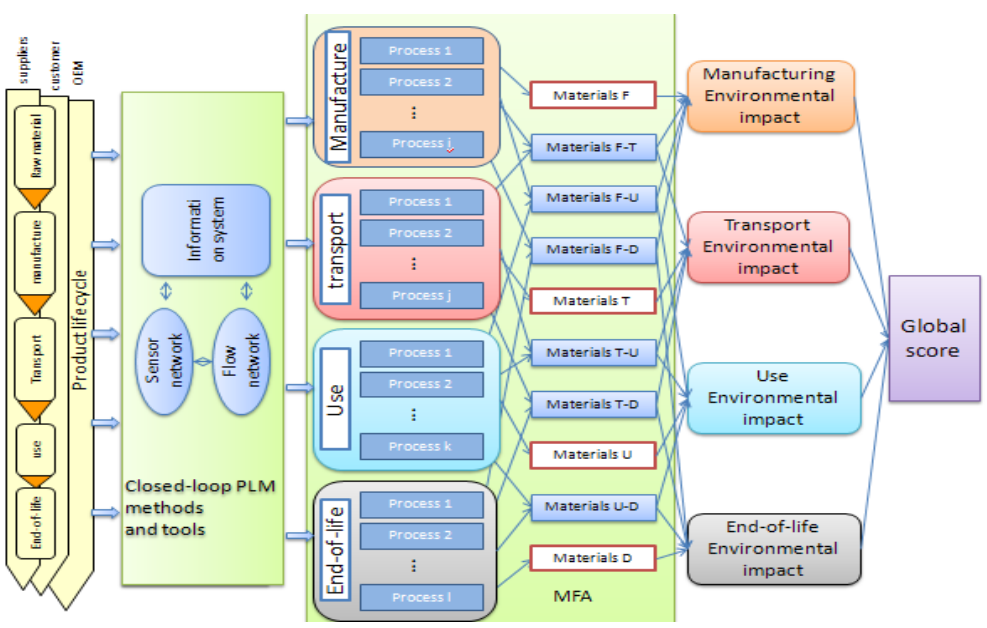

Fig. 2. The model of a product EIs through the whole PLC 
From Figure 2, we can perceive there are different processes in one stage of PLC to make raw materials into a final product. To calculate the EIs of each phase, we can use the formula(2)

$$
D_{i}=\sum p_{i j}\left(M_{i, k}\right) i, k \in[1, n], j \in[1, m]
$$

$D_{i}$ denotes the mass of discharge of $n$ different stages of PLC. At each stage, $m$ processes exist and they will produce discharge based on the materials they dealt with. $p_{i j}$ denotes the function in stage $i$ and process $j$, which can convert the mass of materials into mass of discharge. $M_{i, k}$ denotes the mass of materials dealt in one phase. $i$ and $k$ represent the phase number. The materials in one phase can be divided into two parts. When $i=k, M_{i, k}$, represents the mass of materials only dealt in this phase. When $i \neq k, M_{i, k}$ represents the mass of materials dealt by phase $i$ and phase $k$.

The EIs are come from the discharge materials. We can use formula (3)to calculate the environmental impacts brought by materials in one phase.

$$
E_{i}=\sum D_{i} \times F_{\text {material }}
$$

Where $D_{i}$ represents the materials used in phase $i$.The $F_{\text {material }}$ is represent indicators for each impact category. Pennington [15] gives an example for emission data of how indicators for each impact category can be calculated from inventory data of a product using generic characterization factors shown as formula (4).

$$
F_{\text {material }}=\sum_{s} \text { Characterisation Factor }(s) \times \text { Emission Inventory }(s)
$$

Where the subscript $s$ denotes the materials in the correspond category.

The broad spectrum of approaches in use today in the LCA field are CML (The Dutch Guide to Life Cycle Assessment was developed by the Leiden University Institute of Environmental Sciences), eco-indicator 99 (a project support by The Dutch Ministry of Housing, Spatial Planning and the Environment) , EDIP 97 (Environmental Design of Industrial Products) , EPS 2000 (Environmental Priority Strategies) , impact 2002+, and TRACI ( Tool for the Reduction and Assessment of Chemical and Other Environmental Impacts) [16]. Here the most common characterization factors in each approach are listed in Table 2 to help enterprises choose more suitable method according to their practice.

When we want to get the global EI called global charge (GC) of the product, we can use the formula (5) introduced by Pennington, Potting et al. [15]

$$
E_{\text {global }}=\sum E_{i}
$$

Where $E_{\text {global }}$ is the overall EI score. 
Table 2. Characterization factors in different LCIA methods[16]

\begin{tabular}{|c|c|c|c|c|c|c|}
\hline \multirow[b]{2}{*}{ Impact category } & \multicolumn{2}{|c|}{ Endpoint method } & \multicolumn{4}{|c|}{ Midpoint method } \\
\hline & $\begin{array}{c}\text { Eco- } \\
\text { indicator } \\
99\end{array}$ & EPS 2000 & $\mathrm{CML}$ & EDIP 97 & $\begin{array}{l}\text { Impact } \\
2002+\end{array}$ & TRACI \\
\hline $\begin{array}{c}\text { Climate } \\
\text { protection }\end{array}$ & DALYs & YOLL & GWPs & GWPs & GWPs & GWPs \\
\hline $\begin{array}{c}\text { Stratospheric } \\
\text { Ozone protection }\end{array}$ & DALYs & YOLL & ODPs & ODPs & ODPs & ODPs \\
\hline Acidification & PDFs & No report & APs & APs & none & APs \\
\hline Smog Formation & DALYs & No report & PCOPs & PCOPs & PCOPs & PCOPS \\
\hline Eutrophication & PDFs & No report & $\begin{array}{l}\qquad \mathrm{PO}_{4}^{3-}- \\
\text { equivalents }\end{array}$ & $\begin{array}{l}\qquad \mathrm{NO}_{3}^{-}- \\
\text {equivalents }\end{array}$ & none & \\
\hline
\end{tabular}

DALYs: disability adjusted life years; ODPs: Ozone Depletion Potentials;

PCOPs: Photochemical ozone creation potentials; PDFs: Potentially Disappeared Fraction of species
GWPs: Global Warming Potential.

APs: Acidification Potential

YOLL: Years of Lost Life

\section{Case Study}

Nowadays, with the development of microprocessor technologies, the increasing number of electronic devices used in society [17]. The environmental pollution brought by these devices becomes more serious than before. PCBs are the foundation component of an electronic device, the environmental impact brought by PCB therefore should be studied carefully. Many literatures have already conducted to reduce the PCB's EIs $[18 ; 19 ; 20]$. All of them only focus on one phase of the PCB life cycle, the PTPs not be taken into account. But from these studies, the environmental emission data and formula of each process in fabrication phase is matured. Depending on these studies, users can get relatively accurate environmental emission in each process in the fabrication; the formula can be deduced in other PLC phases such as use, transportation and end-of-life.

Based on the existing studies $[18 ; 21 ; 22]$, the following general processes of the PCB life cycle shown in Figure 3 will be analyzed.

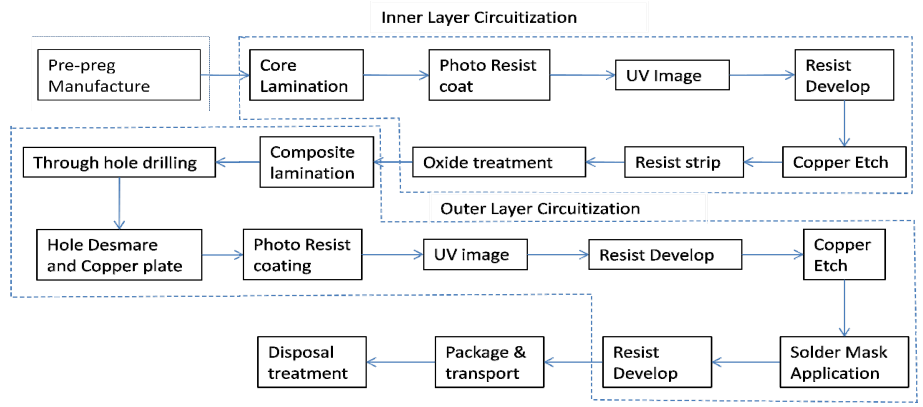

Fig. 3. Process Steps in PCB life cycle 
The first step to do this case study is set the objective and scope. The manufacturing processes of PCB are complex. Enterprises use large amounts of chemicals materials generating numerous types of hazardous wastes. These wastes are potentially harmful to the environment and human health $[23 ; 24]$. The objective of this case study is to evaluate the chemical environmental emission of the PCB production. Based on the existing studies, the significant environmental emission of PCB is mostly coming from three phases: manufacture, transport, and disposal. So the model will focus on these phases.

The second step is to analyze the processes in each phase. Siddhaye, S. and P. Sheng [22] already analysed the manufacture processes of PCB and give out formulas based on general design parameters. Zhu [25] and Morris, Yuracko et al. [26] analysed the processes of transport and disposal respectively. Based on these literatures, we can deduce the formulas in each phase. For example, in the transport phase, the PCBs will be stacked and a polyethylene (PE) film will be sandwiched in every two PCBs. After this, a certain amount of PCBs will put into one boxboard. The mass of per PCB should be calculated by the follow:

$$
m_{\text {pcb }}=t_{\text {prepreg }} \times \rho_{\text {prepreg }} \times A_{\text {panel }}+\sum_{\text {layer }=1}^{\text {layer }=n} t_{c u} \times \rho_{c u} \times A_{\text {core }} \times K_{c u}
$$

Where $t_{\text {prepreg }}$ is the thickness of the substrate, $\rho_{\text {prepreg }}$ is the density of the substrate, $A_{\text {panel }}$ is the area of the panel, $t_{c u}, \rho_{c u}, A_{c o r e}, K_{c u}$ are the thickness of copper, density of copper, area of the core and percentage of copper in each layer respectively.

Then, let $N_{p c b s}$ and $n_{p c b}$ be the number of PCBs put into one boxboard and number of PCBs to be stacked respectively, $w_{b o x}$ be the weight of boxboard, the mass for package one $\mathrm{PCB}$ is:

$$
m_{\text {package }}=\left[\left(n_{p c b}+1\right) / n_{p c b}\right] \times t_{p e} \times \rho_{p e} \times A_{p a n e l}+w_{b o x} / N_{p c b s}
$$

The modeling assumptions made are: the weight of adhesion during the manufacture is slight and not take into account.

The EI during transportation is mainly contributed by the weight of PCB and package, and the weight of one piece packaged PCB is:

$$
m_{\text {pcbpac }}=m_{p c b}+m_{\text {package }}
$$

The third step is to extract the PTP factors. After analysing the process and model the environmental emission of each process in different phase, the PTP factors should be extracted for the further assessment. Based on the formulas produced in processes analysis, we find that different phases of PCB life cycle share same factors which contribute to the environmental load of each phase. In the manufacture phase, the environmental emissions are mostly decided by the copper fraction on different layers and the area of the panel and core. In the transportation phase and disposal phase, the environmental emission is also closely related to these factors. Hence it's clear that the $K_{c u}, A_{\text {core }}, A_{\text {panel }}$ are the PTP factors in this case. 
Finally, we analyze the result of different designs. Considering the PTP factors, we propose two sets of design scheme, they are based on the data coming from a Chinese company[25]. The corresponding results are calculated using the formulas produced in process analysis. Based on the recommendation of the European Commission [27], DALY (Disability-Adjusted Life Year)is the best characterization factor to calculate the potentially harm to the environment and human health. From the characterization factor comparison in Table 2, the most suitable method is Eco-indicator 99. To get a more intuitive EI comparison of the two design schemes, we use Simapro to produce the comparison graph as shown in Figure 4, Figure 5, Figure 6.

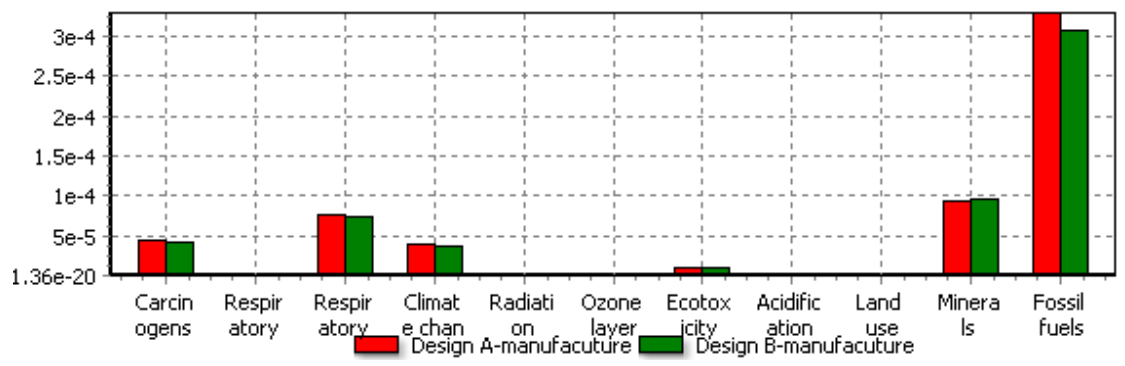

Fig. 4. EI comparison of manufacture using two methods

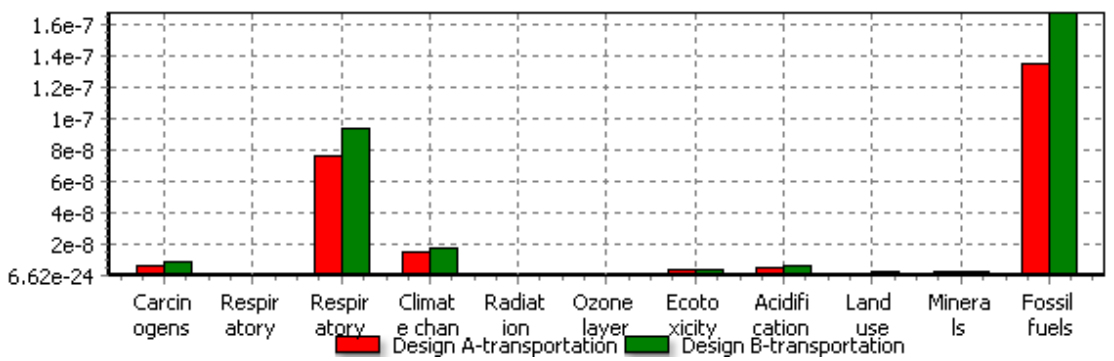

Fig. 5. EI comparison of transportation using two methods

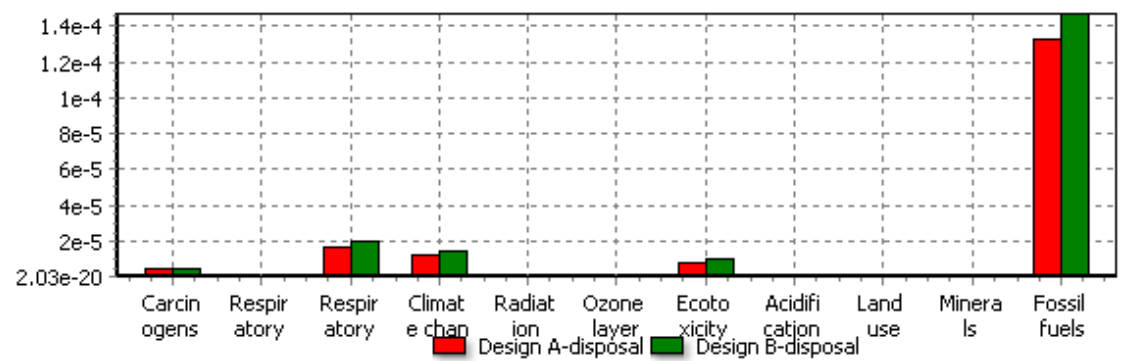

Fig. 6. EI comparison of disposal

From Figure 4, Figure 5, Figure 6, we can see that by considering the PTP in different phases, the EIs of design $\mathrm{A}$ in manufacture are higher than design $\mathrm{B}$, but in transportation and disposal phase, the opposite effects are emerged. 


\section{Conclusion}

This new simplified LCIA model provides an approach to help enterprises assess their products' global EI. By formulating the processes in each phase, the mass of material used in different phases can calculate based on the data get from PLM system. Depend on the formulas, the PTP factors can be abstracted and then the global EI of different designs can then be calculated. The case study using this new model shows that reduce the EIs in one phase may bring an adverse effect in other phases when we take into account the PTP factors. It also proved that by considering the PTP factors in different phases of PLC, the calculation of global EI of product will be more accurate. The model proposed in this paper will provide strong support to improve the global environmental performance of the products.

Acknowledgements. This project has been funded with support from the European Commission Project (EMA2-2010-2359) and Hubert Curien Partnership with Cai Yuanpei China program 2012-2014. This publication reflects the views only of the author, and the Commission cannot be held responsible for any use which may be made of the information contained therein.

\section{References}

1. Chung, J., Lee, H., Koh, Y., Hur, T.: Web based ecodesign supporting system for electronic products. Electronics and the Environment, 246-250 (2003)

2. Hertwich, E.G., Hammitt, J.K.: A decision-analytic framework for impact assessment part I: LCA and decision analysis. The International Journal of Life Cycle Assessment 6(1), 5$12(2001)$

3. Kuo, T.C., Huang, S.H., Zhang, H.C.: Design for manufacture and design for ' $\mathrm{X}$ ': concepts, applications, and perspectives. Computers \& Industrial Engineering 41(3), 241260 (2001)

4. Kaebernick, H., Kara, S., Sun, M.: Sustainable product development and manufacturing by considering environmental requirements. Robotics and Computer-Integrated Manufacturing 19(6), 461-468 (2003)

5. Hauschild, M., Jeswiet, J., Alting, L.: From life cycle assessment to sustainable production: status and perspectives. CIRP Annals-Manufacturing Technology 54(2), 1-21 (2005)

6. Gehin, A., Zwolinski, P., Brissaud, D.: A tool to implement sustainable end-of-life strategies in the product development phase. Journal of Cleaner Production 16(5), 566-576 (2008)

7. Binder, C.R., Van Der Voet, E., Rosselot, K.S.: Implementing the results of material flow analysis. Journal of Industrial Ecology 13(5), 643-649 (2009)

8. Cheah, L., Heywood, J., Kirchain, R.: Aluminum stock and flows in US passenger vehicles and implications for energy use. Journal of Industrial Ecology 13(5), 718-734 (2009)

9. ISO, B.: Environmental management-life cycle assessment-principles and framework. Environmental Management 3(1) (2006)

10. Hur, T., Lee, J., Ryu, J., Kwon, E.: Simplified LCA and matrix methods in identifying the environmental aspects of a product system. Journal of Environmental Management 75(3), 229-237 (2005) 
11. Brezet, H., Van Hemel, C., Böttcher, H., Clarke, R.: Ecodesign: a promising approach to sustainable production and consumption, UNEP (1997)

12. Graedel, T.E., Allenby, B.R.: Design for environment. Prentice Hall, Upper Saddle River (1996)

13. Luttropp, C., Lagerstedt, J.: EcoDesign and the Ten Golden Rules: generic advice for merging environmental aspects into product development. Journal of Cleaner Production 14(15), 1396-1408 (2006)

14. Jun, H.B., Kiritsis, D., Xirouchakis, P.: Research issues on closed-loop PLM. Computers in Industry 58(8-9), 855-868 (2007)

15. Pennington, D., Potting, J., Finnveden, G., Lindeijer, E., Jolliet, O., Rydberg, T., Rebitzer, G.: Life cycle assessment Part 2: Current impact assessment practice. Environment International 30(5), 721-739 (2004)

16. Jane, C., Gloria, T.P.: Critical analysis of the mathematical relationships and comprehensiveness of life cycle impact assessment approaches. Environmental Science \& Technology 40(4), 1104-1113 (2006)

17. Suyang, G., Liu, J.: Life Cycle Assessment on Autoliv's Electronic Control Unit (2010)

18. Worhach, P., Sheng, P.: Integration of environmental factors in process modeling for printed circuit board manufacturing. I. Assembly. In: Electronics and the Environment, ISEE 1997, pp. 218-225. IEEE (1997)

19. Hertwich, E.G., Sheng, P., Koshland, C.P.: A flexible method for including environmental toxicity in DFE and LCA. In: Proceedings of the 1996 IEEE International Symposium on Electronics and the Environment, ISEE 1996, pp. 269-274. IEEE (1996)

20. Xiang, D., Mou, P., Wang, J., Duan, G., Zhang, H.C.: Printed circuit board recycling process and its environmental impact assessment. The International Journal of Advanced Manufacturing Technology 34(9), 1030-1036 (2007)

21. Kanth, R.K., Liljeberg, P., Tenhunen, H., Wan, Q., Zheng, L.: Insight into quantitative environmental emission analysis of printed circuit board. In: 2011 10th International Conference on Environment and Electrical Engineering (EEEIC), pp. 1-4. IEEE (2011)

22. Siddhaye, S., Sheng, P.: Integration of environmental factors in process modelling for printed circuit board manufacturing. II. Fabrication. In: Proceedings of the 1997 IEEE International Symposium on Electronics and the Environment, ISEE 1997, pp. 226-233. IEEE (1997)

23. Hui, I., Li, C., Lau, H.: Hierarchical environmental impact evaluation of a process in printed circuit board manufacturing. International Journal of Production Research 41(6), 1149-1165 (2003)

24. Kirsch, F.W.: Waste Minimization Assessment for Multilayered Printed Circuit Board Manufacturing (1991)

25. Zhu, G.: The study of evaluating environmental impacts in printed circuit board manufacturing, tainan, National Cheng Kung University (2001)

26. Morris, M.I., Yuracko, K.L., Govers, R.A., Maynor, D.M., Altmayer, S.: Life Cycle Analysis for Treatment and Disposal of PCB Waste at Ashtabula and Fernald, ORNL/TM2000/254, Oak Ridge National Laboratory, Oak Ridge, TN (2000)

27. European-Commission. International Reference Life Cycle Data System (ILCD) Handbook-Recommendations for Life Cycle Impact Assessment in the European context, 1st edn. (November 2011) 